\title{
Learning to read facilitates the retrieval of phonological representations in rapid automatized naming: Evidence from unschooled illiterate, ex-illiterate, and schooled literate adults
}

\author{
Susana Araújo $^{1}$ | Tânia Fernandes ${ }^{1}$ | Falk Huettig ${ }^{2}$
}

${ }^{1}$ Faculdade de Psicologia, Universidade de Lisboa, Lisbon, Portugal

${ }^{2}$ Max Planck Institute for Psycholinguistics, Nijmegen, The Netherlands

Correspondence

Susana Araújo, Faculdade de Psicologia, Universidade de Lisboa, Lisboa, Portugal. Email:smaraujo@psicologia.ulisboa.pt

Funding information

Fundação para a Ciência e a Tecnologia, Grant/Award Number: 028184 and IF/00533/2015; Fundação Bial, Grant/ Award Number: ref A-04125, Project no 180/14; Universidade de Lisboa; Project VOrtEx

\begin{abstract}
Rapid automatized naming (RAN) of visual items is a powerful predictor of reading skills. However, the direction and locus of the association between RAN and reading is still largely unclear. Here, we investigated whether literacy acquisition directly bolsters RAN efficiency for objects, adopting a strong methodological design, by testing three groups of adults matched in age and socioeconomic variables, who differed only in literacy/schooling: unschooled illiterate and ex-illiterate, and schooled literate adults. To investigate in a fine-grained manner whether and how literacy facilitates lexical retrieval, we orthogonally manipulated the word-form frequency (high vs. low) and phonological neighborhood density (dense vs. spare) of the objects' names. We observed that literacy experience enhances the automaticity with which visual stimuli (e.g., objects) can be retrieved and named: relative to readers (ex-illiterate and literate), illiterate adults performed worse on RAN. Crucially, the group difference was exacerbated and significant only for those items that were of low frequency and from sparse neighborhoods. These results thus suggest that, regardless of schooling and age at which literacy was acquired, learning to read facilitates the access to and retrieval of phonological representations, especially of difficult lexical items.

KEYWORDS

lexical dynamics, literacy acquisition, neighborhood density, rapid naming, word-form frequency
\end{abstract}

\section{1 | INTRODUCTION}

Rapid automatized naming (RAN) is an ability at the interface of visual recognition and speech production and one of the most influential constructs in learning to read. This ability is assessed by simple tasks where participants name an array of letters, digits, objects, or colors as quickly as possible (Denckla \& Rudel, 1976) and the total time necessary to name the whole array is typically interpreted as a proxy of the automaticity by which familiar stimuli and their phonological codes are accessed and retrieved (Chiappe, Stringer, Siegel, \& Stanovich, 2002; Clarke, Hulme, \& Snowling, 2005; Schatschneider, Carlson, Francis, Foorman, \& Fletcher,
2002; Torgesen, Wagner, \& Rashotte, 1994). RAN is a powerful predictor of growth in reading across development, reading abilities, and languages (Caravolas, Lervåg, Defior, Málková, \& Hulme, 2013; Landerl et al., 2013; Moll et al., 2014; Vaessen et al., 2010; Ziegler et al., 2010), beyond the effect of phonological awareness and short-term memory, letter knowledge, vocabulary, and IQ (Georgiou, Parrila, \& Kirby, 2009; Kirby, Parrila, \& Pfeiffer, 2003; Powell, Stainthorp, Stuart, Garwood, \& Quinlan, 2007). Slowed RAN is also a core, persistent feature in developmental dyslexia (Denckla \& Rudel, 1976; Wolf \& Bowers, 1999; Wolf, Bowers, \& Biddle, 2000), the most common learning disorder characterized by specific but severe difficulties in learning to read. 
A recent meta-analysis confirmed the moderate-to-strong positive correlation between RAN and reading, $r=0.43$ (Araújo, Reis, Petersson, \& Faísca, 2015). This is (at least partly) expected as performance in both tasks share cognitive processes and neural underpinnings (Lau et al., 2015; Lervåg \& Hulme, 2009; Misra, Katzir, Wolf, \& Poldrack, 2004; Price et al., 2006). Both RAN and reading involve saccadic programming, multiple-item sequencing, executive attentional mechanisms, visual object recognition (from initial feature detection to access to abstract object representations), and speech production processes (Norton \& Wolf, 2012). However, the direction and nature of causality between reading and RAN remains unclear; this is the purpose of the present study.

Whereas, some developmental studies reported a unidirectional effect of (early) RAN on later reading skills (Lervåg \& Hulme, 2009; Verhagen, Aarnoutse, \& van Leeuwe, 2008; Wei, Georgiou, \& Deng, 2015), others found a reciprocal relation between RAN and reading (Compton, 2003; Peterson et al., 2017; Wolff, 2014), and hence, reading experience is not only influenced by but is also a causal influence on RAN (cf. Huettig, Lachmann, Reis, \& Petersson, 2018). Indeed, in a recent longitudinal study from prekindergarten to fourth-grade, Peterson et al. (2017) did find evidence for a causal effect of early reading skills on children's RAN but only at the very beginning of literacy acquisition (while the relation was reversed in older children). Interestingly, this influence was unlikely to be merely driven by increased automaticity of letter retrieval due to literacy instruction, given that it extended to nonalphanumeric RAN. Other studies also suggest a causal role of literacy on RAN: Compton (2003) found such relation, especially for first-graders who were still unable to read at the first testing moment. Furthermore, phonics training (i.e., in phonemic awareness and decoding, reading fluency, and comprehension) significantly enhanced RAN in third-graders with reading difficulties (Wolff, 2014). Taken together these longitudinal studies can best be summarized as evidence for a bidirectional relationship between reading and RAN. It is important to note, however, that although longitudinal designs are usually powerful (Goswami, 2015; Huettig et al., 2018), the literacy-RAN link is moderated by development and thus intrinsically confounded with neural maturation and also with schooling in such studies. Therefore, these studies preclude the possibility to examine in a fine-grained manner the causal-consequence direction from learning to read to RAN. There are other ways to study how the acquisition of literacy shapes the human brain and mind (e.g., tightly controlled crosssectional studies with preliterate children; and comparing illiterate unschooled adults) but each of these designs have strengths and weaknesses (cf. Dehaene, Cohen, Morais, \& Kolinsky, 2015). The most convincing evidence will come from studies with complementary designs that provide converging evidence. The aim of the present study was thus to directly examine the influence of literacy on the efficiency of RAN for objects, comparing for the first time three groups of adults matched in age, socioeconomic, cultural, and residential backgrounds, who differed only on literacy and schooling: unschooled illiterate (who did not attend school

\section{RESEARCH HIGHLIGHTS}

- Learning to read and write directly enhances rapid automatic naming of visual objects, independently of maturation and general education.

- Literacy assists faster access to phonological lexical representations of hard items (i.e., words with low-frequency or from sparse neighborhoods).

- This literacy-driven effect appears to occur through support provided by orthographic knowledge.

nor learned to read and write strictly due to socioeconomic and cultural reasons), unschooled ex-illiterate (who, like the illiterate, did not attend school but learned to read during adulthood in alphabetization courses), and schooled literate adults (who learned to read during childhood in regular schooling). In this way we were able to examine whether learning to read influences the efficiency of RAN, regardless of schooling and developmental constrains, thus complementing prior studies with children.

To investigate in a fine-grained manner how literacy may influence lexical retrieval for production, we also orthogonally manipulated two psycholinguistic dimensions of objects' names known to influence lexical dynamics. Specifically, word-form frequency (high vs. low) and neighborhood density (i.e., number of words that differ in one-phoneme, by addition, deletion, or substitution; an index of how phonologically similar one word is to others in the mental lexicon; for a review, see Vitevitch \& Luce, 2016). In previous research on spoken word recognition, illiterate adults were as sensitive to these psycholinguistic dimensions as literate adults, suggesting similar lexical dynamics irrespective of the reading level: all showed better and faster recognition of high-frequency words from sparse than dense neighborhoods (i.e., with few than many phonological neighbors, respectively), and of low-frequency words from dense than sparse neighborhoods (Ventura, Kolinsky, Fernandes, Querido, \& Morais, 2007). To the best of our knowledge no study has hitherto examined the role of these psycholinguistic dimensions on RAN. In the present study, participants were thus asked to name four types of matrices comprising objects of each of the four conditions of Word-form frequency $\times$ Neighborhood density.

Regarding word-form frequency, we expected participants to name the objects with high-frequency names faster than those with low-frequency names (e.g., Jescheniak \& Levelt, 1994). We also hypothesized that learning to read modulates this word-form frequency effect, given that literacy experience establishes interconnections between phonological and orthographic representations (Ehri, 2014; Kolinsky, 2015) and, possibly, may even result in deep lexical restructuring of phonological representations (i.e., the emergence of more fine-grained, phonetic representations of words; Goswami, 2000; Smith, Monaghan, \& Huettig, 2014; Ziegler \& Goswami, 2005). More efficient retrieval and/or restructuring of phonological 
representations promoted by literacy therefore should support better word-form retrieval during RAN tasks. We thus expected illiterate adults to perform worse on RAN compared to ex-illiterate and literate but only for low-frequency items, not for high-frequency ones. This Literacy $\times$ Word-form frequency interaction would reflect an impact of literacy on lexical access and retrieval, as this frequency effect is mainly a word-form level phenomenon (Jescheniak \& Levelt, 1994; Levelt, 2001; Meyer, Sleiderink, \& Levelt, 1998; but see Kittredge, Dell, Verkuilen, \& Schwartz, 2008; Mousikou \& Rastle, 2015).

Regarding phonological neighborhood density, a prediction is less straightforward because this effect has been volatile in speech production: from facilitatory, null, to inhibitory (e.g., Newman \& German, 2005; Sadat, Martin, Costa, \& Alario, 2014; Vitevitch, 1997). This also applies to any interaction between literacy and neighborhood density on RAN. Nonetheless, one might conjecture that the difference between illiterate versus literate groups would be the largest for items from sparse-neighborhoods (Metsala, 1997; Muneaux \& Ziegler, 2004), because there is more room for an additional influence of literacy experience beyond that of spoken vocabulary growth for these items (Garlock, Walley, \& Metsala, 2001; Walley, Metsala, \& Garlock, 2003). This pattern of results could be due to the support of orthographic representations or due to restructuring of (sparse) phonological representations (Ziegler \& Goswami, 2005).

Importantly, the critical comparison of illiterate versus ex-illiterate groups in this study, both unschooled and with similar vocabulary size (cf. Morais \& Kolinsky, 2001), allows to disentangle the effect of literacy from that of education and lexical knowledge on RAN. We also ensured that familiarity with the experimental items was similar between groups (see Section 2), and so any interaction with literacy would not be due to illiterate's reduced experience with specific words.

\section{2 | MATERIAL AND METHODS}

\section{1 | Participants}

Forty-six Portuguese adults from the same socioeconomic, cultural, and residential backgrounds were paid for their participation (the same sampling method as that of prior studies was adopted, cf. Kolinsky et al., 2011). According to literacy/schooling, participants were assigned to three groups, matched in age, $F(2,43)<1: 16$ illiterate (13 women; $M_{\text {age }}=37.1$ years, $S D=8.1$ ); 14 unschooled ex-illiterate (eight women; $\left.M_{\text {age }}=41.9, S D=11.1\right) ; 16$ schooled literate (11 women; $M_{\text {age }}=37.0$, $S D=12.9)$ with, on average, 8 years of formal education $(S D=3.3)$

None of the illiterate adults was able to read even simple words or pseudowords (reading fluency test; Pacheco et al., 2014), but they varied on letter knowledge (on average, eight out of the 23 letters of the Portuguese alphabet, $S D=5.7$ ). Importantly, neither illiterate or the other groups had evidence of significant cognitive or neurodevelopmental problems ( $F<1$ in the Mini-Mental State Examination; Portuguese version: Guerreiro et al., 1994). It was only for cultural and socioeconomic reasons that they did not attend school nor receive reading instruction. Illiterate participants were recruited through nongovernmental agencies or were at the very beginning (first 2 weeks) of alphabetization classes, before reading instruction starts. Both ex-illiterate and schooled literate were recruited with the help of the same agencies and were from the same residential area (in some cases, from the same families as the illiterate). Ex-illiterate adults already had finished the (fourth) final level of the alphabetization course. Both ex-illiterate and literate participants correctly identified all the 23 letters and read accurately at least $82 \%$ of the words and pseudowords. Yet, as expected, ex-illiterate read less items per minute than literate adults (words: ex-illiterate, $M=0.78, S D=0.36$; literate, $M=1.4$, $S D=0.53$, pseudowords: ex-illiterate, $M=0.50, S D=0.22$; literate, $M=0.81, S D=0.29$; both $p s<0.001$ )

\section{2 | Materials and design}

The object-RAN task was based on the original RAN paradigm (Denckla \& Rudel, 1976). Hence, we used many repetitions of a small set of items as the main interest is on the issue of skill automatization (Norton \& Wolf, 2012). Note that using a small set does not preclude the finding of a robust RAN-reading association (for a meta-analysis, see Araújo et al., 2015). Line drawings of 20 objects were selected from the MPI database according to the 2 Word-form frequency (high vs. low) $\times 2$ Phonological neighborhood density (dense vs. sparse) of objects' names. The four experimental conditions differed on frequency of occurrence ( $M: 42$ vs. 3 per million for high-frequency vs. low-frequency; SUBTLEX-PT database; Soares et al., 2015) and neighborhood density (M: 8.3 vs. 1.5 neighbors for dense vs. sparse neighborhoods; P-PAL: Soares, Costa, Machado, Comesaña, $\&$ Oliveira, 2017). They were matched ( $t$ tests, all $p s>0.12$ ) in orthographic and phonological length, orthographic neighborhood density (Soares et al., 2017), neighbors' frequency, and on pictures' visual complexity (Szekely \& Bates, 2000). See Appendix A for the complete list of items and their characteristics.

Objects were arranged in four sets of matrices corresponding to the orthogonal manipulation of word-form frequency and neighborhood density. Each matrix comprised 30 items arranged in a $6 \times 5$ layout (so each object was repeated six times with order pseudorandomized, with the criteria that no consecutive objects had names that shared initial phonemes). Two matrices for each set (same objects but in a different arrangement) were presented to participants (see Figure 1: illustration of a matrix of the high-frequency and dense neighborhood set); the order of the four sets of matrices followed a Latin square design.

Stimuli's presentation and data collection were controlled by EPrime. Participants were first given a practice session. Labels other than those expected were corrected. Participants were instructed to name the stimuli as quickly and accurately as possible in a leftto-right and down fashion. Response time (RT) was computed as the mean time necessary to name the items of the two matrices.

At the end of the session, participants were asked for subjectivefamiliarity 1-7 rating on all objects. Importantly, the three groups did not differ on their ratings of the objects, $F<1$. All groups showed 
a significant effect of word frequency, $F(1,43)=289.8, p<0.001$, which was not modulated by literacy, $F<1$. The same happened for neighborhood density: Group $x$ Neighborhood, $F=1.3, p=0.28$ (G roup $\times$ Frequency $\times$ Neighborhood, $F<1$ ). In sum, illiterates had the same familiarity with the items as the ex-illiterate and literate group, and all participants were equally sensitive to word-form frequency, rating high-frequency words as more familiar than low-frequency words. This result is not surprising given the association between familiarity (subjective measure) and word frequency (e.g., Carroll, 1971).

\section{3 | RESULTS}

Accuracy was close to ceiling ( $>98 \%$ for all groups) and the groups did not differ significantly, $F<1$. In the mixed Group $\times$ Frequen cy $\times$ Neighborhood ANOVA run on mean RTs (see Table 1 ), main effects of Group, $F(2,43)=8.51, p<0.005, \eta p^{2}=0.28$, and Frequency, $F(1,43)=34.19, p<0.001, \eta p^{2}=0.44$, were observed. Importantly, the three-way interaction was not significant, $F<1$, but the Group $\times$ Frequency interaction was, $F(2,43)=3.64$, $p=0.035, \eta p^{2}=0.15$. All groups showed robust word frequency effects (all $p s \leq 0.013$ ). Bonferroni post hoc tests showed that for high-frequency words, illiterate did not differ significantly from readers (vs. ex-illiterate, $p=0.613$; vs. literate, $p=0.199$; ex-illiterate vs. literate: $p=0.99$ ). However, for low-frequency words, illiterate adults were significantly slower than ex-illiterate $(p=0.002)$ and literate $(p=0.001)$, which in turn did not differ from each other $(p=0.99)$. In fact, the Group $\times$ Frequency interaction was still significant when considering unschooled illiterate versus ex-illiterate adults only, $F(1,43)=6.04, p=0.018$. This pattern of results suggests that learning to read (regardless of schooling or age at which literacy was acquired) facilitates lexical access, especially for items with low frequency. Furthermore, given that illiterate had the same subjective familiarity with low-frequency items as ex-illiterate and literate (see Section 2), these results cannot be due to less experience with low-frequency words by nonreaders.

The Group $\times$ Neighborhood interaction was also significant, $F(2$, 43) $=4.16, p=0.022, \eta p^{2}=0.16$ (all other $F s<1$ ) and, again, was also observed when illiterate were compared to ex-illiterate adults only, $F(1,43)=8.30, p=0.006$. However, there was no main effect of neighborhood density for any group (all ps $>0.25$ ). The advantage of readers (either ex-illiterate or literate) over illiterate adults on RAN was only robust for items from sparse neighborhoods (both $p s \leq 0.003$; ex-illiterate vs. literate, $p=0.99$ ), but not for those from dense ones (vs. ex-illiterate: $p=0.89$; vs. literate: $p=0.08$; ex-illiterate vs. literate, $p=0.99$ ).

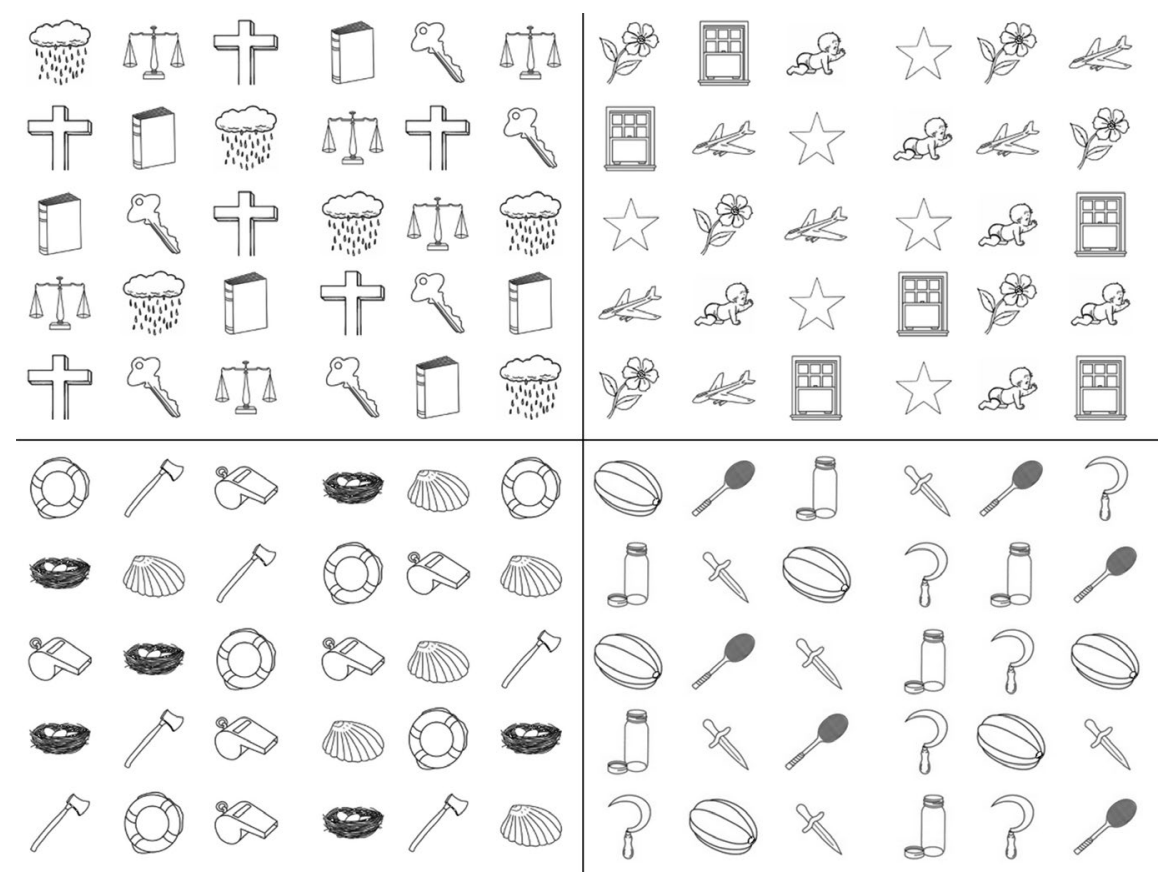

\begin{tabular}{lllllll} 
& \multicolumn{2}{l}{ High frequency names } & & \multicolumn{2}{l}{ Low frequency names } \\
\cline { 2 - 3 } \cline { 6 - 7 } & Dense PN & Sparse PN & & Dense PN & Sparse PN \\
Illiterates & $26,914(767)$ & $28,361(1,355)$ & & $31,861(1,219)$ & $34,063(2,570)$ \\
\hline Ex-illiterates & $24,892(1577)$ & $23,186(1,271)$ & & $27,260(1803)$ & $24,714(1,325)$ \\
\hline Literates & $22,939(666)$ & $23,845(734)$ & & $26,141(961)$ & $25,551(992)$ \\
\hline
\end{tabular}

FIGURE 1 Example display of one trial of the RAN task, for high-frequency object names with dense (top left) versus sparse neighborhoods (top right) and low-frequency object names with dense (bottom left) versus sparse neighborhoods (bottom right)

TAB LE 1 Mean total naming times (with standard errors) as a function of neighborhood density and frequency of the objects' name, separately by group

Note. PN, Phonological neighborhood density. 
The interpretation that there is a direct association between literacy and object RAN is further supported by the significant correlation between word-reading fluency of ex-illiterate and literate adults and RAN (unilateral test), $r(28)=-0.329, p=0.038$ : the better their reading fluency, the faster their RAN performance. This correlation cannot be due to an overall difference in speed between these two groups, as they did not differ in any way on RAN ( $F s<1)$.

\section{4 | DISCUSSION}

In the present work, we found novel evidence that learning to read enhances the automaticity with which visual stimuli (e.g., objects) and their names can be accessed and retrieved. By comparing earlyschooled literate with a group of late-literate and completely illiterate adults, we provide here the first direct demonstration that: (a) literacy acquisition has a specific facilitatory effect on lexical access, as measured by RAN, and that (b) this effect cannot be attributed to general education but is a consequence of literacy. The specific gain in RAN was observed likewise for adults who acquired literacy during adulthood (i.e., unschooled ex-illiterate) and early-schooled literate over illiterate participants, showing that rudimentary reading skills suffice to attain automaticity in RAN. The fact that the two literate groups did not differ from each other further suggests that literacy acquisition influences RAN but probably only at early phases of reading development. This main finding is at odds with the notion that RAN taps a basic (unidirectional) causal influence on reading development (e.g., Lervåg \& Hulme, 2009; Verhagen et al., 2008; Wei et al., 2015), while it concurs with recent studies on school-age children that showed an influence of earlier literacy on the growth of later RAN (Compton, 2003; Peterson et al., 2017; Wolff, 2014). The observed correlation between word-reading fluency of ex-illiterate and literate adults and their performance on RAN supports this conclusion.

By orthogonally manipulating word-form frequency and phonological neighborhood density of the object's names during RAN, we tested in a fine-grained manner the influence of literacy on online lexical processing. On average, illiterate were slower in RAN (see Table 1). But crucially, the literacy advantage on online lexical processing was only reliable for objects with low-frequency names or names from sparse neighborhoods. In contrast, there was no significant difference between the three literacy groups when naming objects with high-frequency names or from dense neighborhoods.

In what regards lexical dynamics, we replicated the finding that general sensitivity to word frequency does not depend on learning to read (Ventura, Kolinsky, Fernandes, et al., 2007), that is, illiterate in our study were as sensitive to word frequency as the literate groups. Regardless of the availability (or not) of orthographic representations, high-frequency words have an advantage in lexical processing over low-frequency words, and hence, any assistance promoted by literacy in access and retrieval of the former words would be barely visible. This is markedly different for low-frequency words. In this case lexical knowledge acquired through oral context does not help much. Therefore, interconnections between phonological and orthographic representations fostered by literacy (Ehri, 2014; Kolinsky, 2015; Rastle, McCormick, Bayliss, \& Davis, 2011; Ziegler \& Goswami, 2005) lead to more efficient retrieval of lowfrequency words, as reflected by a significant advantage on lexical access and retrieval of these items by readers over nonreaders. The present results suggest that more efficient lexical retrieval of phonological representations is a consequence of literacy acquisition, likely through the support provided by orthographic knowledge (Rastle et al., 2011; Ziegler \& Goswami, 2005).

The notion of a role of orthography in spoken word production is not new though has received less attention than in spoken word recognition. Our findings are in line with prior studies that showed influences of orthography in production by comparing the performance of literate participants on different sets of words (e.g., Rastle et al., 2011; Saletta, Goffman, \& Brentari, 2016). The originality of the present study regards the strong methodological design it offered: controlling for possible confounds of formal education and related experiences, and as much as possible of maturation and cognitive development (by comparing two matched populations equally deprived of early schooling, ex-illiterate vs. illiterate), while dispensing the between-item designs for testing literacy effects, necessary when all participants are readers. Note, however, that it is not that the present design is without limitations, but crucially, it provides complementary and converging evidence to studies with other designs, including longitudinal approaches with children (Peterson et al., 2017). Our findings suggest that, as a consequence of literacy, an increasingly efficient access to phonological representations results in better word-form retrieval during RAN tasks, which underlies the observed relationship between reading skills and RAN. This may also explain the better performance of readers than nonreaders in phonological working-memory and pseudoword repetition tasks (Demoulin \& Kolinsky, 2016; Kosmidis, Kyrana, \& Folia, 2006; Kosmidis, Zafiri, \& Politimou, 2011; Reis \& Castro-Caldas, 1997; Reis, Guerreiro, \& Peterson, 2003).

The same interpretation applies to the interaction found here between literacy and phonological neighborhood density. Although there was no significant main effect of neighborhood density on RAN and neither for any of the groups separately, it was only for items from sparse neighborhoods that illiterate adults were slower than readers. The effect of phonological neighborhood density has been equivocal in speech production (Chen \& Mirman, 2012; Newman \& German, 2005; Sadat et al., 2014; Vitevitch, 1997), but some studies found an advantage of items from dense over sparse neighborhoods in (discrete) naming tasks (for a review, see Vitevitch \& Luce, 2016). Furthermore, studies with illiterate adults showed that they are able to develop phonemically structured lexical representations for words from dense neighborhoods like literate adults (Ventura, Kolinsky, Fernandes, et al., 2007). Words from sparse neighborhoods do not benefit to the same extent from oral vocabulary knowledge as those from dense neighborhoods, and hence, the former benefit the most from orthographic feedback brought about by literacy (Ehri, 2014; 
Kolinsky, 2015; Muneaux \& Ziegler, 2004). The modulation of literacy on neighborhood density parallels the one we found on word-form frequency because both psycholinguistic properties affect the speed of word-form retrieval at the lexical level (Buz \& Jaeger, 2016; Jescheniak \& Levelt, 1994; Levelt, 2001; Meyer et al., 1998). Specifically, this literacy-driven advantage originates from facilitation of lexical access and retrieval of hard lexical items, that is, those from sparse neighborhoods or low-frequency ones, and eventually extends to other psycholinguistic properties that hinder lexical access (e.g., items with late age of acquisition).

Prior studies also argue for this conclusion. Ventura et al. (Ventura, Kolinsky, Fernandes, et al., 2007; Ventura, Kolinsky, Querido, Fernandes, \& Morais, 2007) observed that, on spoken word recognition tasks (gating and identification-in-noise), more of the speech input needs to unfold for the illiterate participants to recognize words, and on cross-modal picture-word interference, the phoneme priming effect emerges at a later stimulus onset asyncrony (SOA) in illiterate than ex-illiterate adults. In other words, nonreaders require more speech signal to get the same lexical effects as readers, suggesting that literacy boosts the access to the mental lexicon even though (at least apparently) the groups did not differ in the phonological nature of their lexical representations (see also Huettig, Singh, \& Mishra, 2011).

Nonetheless, it could be argued that the effects of literacy found here on RAN for hard lexical items could rather be due to less experience by illiterate adults with such words, or merely because of general slower processing. Both are, however, extremely unlikely. All groups had the same subjective familiarity ratings (see Section 2) including for low-frequency items and for those from sparse neighborhoods. Furthermore, this specific disadvantage by illiterate held true even when compared with ex-illiterate adults: both groups are unschooled and less familiarized with test-taking situations than schooled participants; they only differed on reading skills. Given that both unschooled groups were illiterate for a large part of their life, it is also extremely unlikely that the present results could be attributed to vocabulary size (cf. Morais \& Kolinsky, 2001). In sum, the present results fit best with the notion that learning to read enhances the efficiency of phonological name retrieval thereby improving RAN. Future research could usefully explore this further by looking at the effects of literacy longitudinally (for recent evidence, see Kolinsky, Leite, Carvalho, Franco, \& Morais, 2018), by adopting for example random assignment of illiterate adults to literacy training.

By revealing that important aspects of RAN performance are at least partially a consequence of reading experience, the current findings also draw attention to possible limits of RAN tasks for diagnostic purposes (cf. Peterson et al., 2017) and may cause researchers to revisit the causal role of RAN in developmental dyslexia (cf. Huettig et al., 2018). Relatedly, these results can be relevant for neuropsychological/psychoeducational assessment. Given that low-frequency words or items from sparse phonological neighborhoods are less immune to the impact of literacy skills, these items can exacerbate differences in RAN between typical and dyslexic readers not because of the reading disorder itself but as consequence of reading level.
To conclude, the take-home message of our work is that: (a) learning to read enhances online RAN of visual objects, and (b) this occurs because learning to read results in more efficient access to phonological representations, probably because of automatic coactivation of orthographic representations. These effects are thus especially visible for hard lexical items.

\section{ACKNOWLEDGEMENTS}

The first author and this work were supported by IF 2015 Program of the Portuguese Foundation for Science and Technology, FCT (ref. IF/00533/2015) and by the Research Center for Psychological Science at Universidade de Lisboa (CICPSI), as well as by the Project VOrtEx (ref 028184) funded by FCT, Portugal2020, and FEDER \& FEEI - European Union. This work was also supported by a scientific project funded by Bial Foundation (ref A-04125, Project no 180/14). We thank Centro de Desenvolvimento Comunitário da Ameixoeira, Lisboa, Project K'Cidade (Dra. Ana Melo), Câmara Municipal de Beja (especially to Dra. Cristina Taquelim) and Cáritas Diocesana de Beja (Dra. Mariana Côco) for their assistance in participant's recruitment and Margarida Cipriano for assistance on data collection.

\section{CONFLICT OF INTEREST}

The Authors declare no conflict of interest.

\section{ENDNOTE}

${ }^{1}$ Other metrics have been considered in the definition of phonological neighborhood. Nonetheless, the one-phoneme metric used here is the most popular estimation procedure (Luce, David, \& Stephen, 1990; Vitevitch \& Luce, 2016).

\section{REFERENCES}

Araújo, S., Reis, A., Petersson, K. M., \& Faísca, L. (2015). Rapid automatized naming and reading performance: A meta-analysis. Journal of Educational Psychology, 107, 868-883. https://doi.org/10.1037/ edu0000006

Buz, E., \& Jaeger, T. F. (2016). The (in)dependence of articulation and lexical planning during isolated word production. Language, Cognition and Neuroscience, 31(3), 404-424. https://doi.org/10.1080/232737 98.2015.1105984

Caravolas, M., Lervåg, A., Defior, S., Málková, G. S., \& Hulme, C. (2013). Different patterns, but equivalent predictors, of growth in reading in consistent and inconsistent orthographies. Psychological Science, 24(8), 1398-1407. https://doi.org/10.1177/0956797612473122

Carroll, J. B. (1971). Measurement properties of subjective magnitude estimates of word frequency. Journal of Verbal Learning and Verbal Behavior, 10(6), 722-729. https://doi.org/10.1016/ S0022-5371(71)80081-6

Chen, Q., \& Mirman, D. (2012). Competition and cooperation among similar representations: Toward a unified account of facilitative and inhibitory effects of lexical neighbors. Psychological Review, 119(2), 417-430. https://doi.org/10.1037/a0027175 
Chiappe, P., Stringer, R., Siegel, L. S., \& Stanovich, K. E. (2002). Why the timing deficit hypothesis does not explain reading disability in adults. Reading and Writing: an Interdisciplinary Journal, 15, 73-107. https:// doi.org/10.1023/A:1013868304361

Clarke, P., Hulme, C., \& Snowling, M. J.(2005). Individual differences in RAN and reading: A response timing analysis. Journal of Research in Reading, 28, 73-86. https://doi.org/10.1111/j.1467-9817.2005.00255.x

Compton, D. L. (2003). Modeling the relationship between growth in rapid naming speed and growth in decoding skill in first-grade children. Journal of Educational Psychology, 95(2), 225-239. https://doi. org/10.1037/0022-0663.95.2.225

Dehaene, S., Cohen, L., Morais, J., \& Kolinsky, R. (2015). Illiterate to literate: Behavioural and cerebral changes induced by reading acquisition. Nature Reviews Neuroscience, 16, 234-244. https://doi. org/10.1038/nrn3924

Demoulin, C., \& Kolinsky, R. (2016). Does learning to read shape verbal working memory? Psychonomic Bulletin \& Review, 23, 703-722. https://doi.org/10.3758/s13423-015-0956-7

Denckla, M. B., \& Rudel, R. G. (1976). Rapid "automatized" naming (R.A.N.): Dyslexia differentiated from other learning disabilities. Neuropsychologia, 14, 471-479. https://doi. org/10.1016/0028-3932(76)90075-0

Ehri, L. C. (2014). Orthographic mapping in the acquisition of sight word reading, spelling memory, and vocabulary learning. Scientific Studies of Reading, 18(1), 5-21. https://doi.org/10.1080/10888438.2013.81 9356

Garlock, V. M., Walley, A. C., \& Metsala, J. L. (2001). Age-of-acquisition, word frequency, and neighborhood density effects on spoken word recognition by children and adults. Journal of Memory and Language, 45, 468-492. https://doi.org/10.1006/jmla.2000.2784

Georgiou, G. K., Parrila, R., \& Kirby, J. (2009). RAN components and reading development from grade 3 to grade 5 : What underlies their relationship? Scientific Studies of Reading, 13(6), 508-534. https://doi. org/10.1080/10888430903034796

Goswami, U. (2000). Phonological representations, reading development and dyslexia: Towards a cross-linguistic theoretical framework. Dyslexia, 6, 133-151. https://doi.org/10.1002/ (SICI)1099-0909(200004/06)6:2<133:AID-DYS160>3.0.CO;2-A

Goswami, U. (2015). Sensory theories of developmental dyslexia: Three challenges for research. Nature Review Neuroscience, 16(1), 43-54. https://doi.org/10.1038/nrn3836

Guerreiro, M., Silva, A. P., Botelho, M., Leitão, O., Castro-Caldas, A., \& Garcia, C. (1994). Adaptação portuguesa da tradução do Mini Mental State Examination (MMSE) [Adaptation to the Portuguese population of the translation of the Mini Mental State Examination (MMSE)]. Revista Portuguesa De Neurologia, 1, 9-10.

Huettig, F., Lachmann, T., Reis, A., \& Petersson, K. M. (2018). Distinguishing cause from effect - Many deficits associated with developmental dyslexia may be a consequence of reduced and suboptimal reading experience. Language, Cognition and Neuroscience, 33, 333-350. https://doi.org/10.1080/23273798.2017.1348528

Huettig, F., Singh, N., \& Mishra, R. K. (2011). Language-mediated visual orienting behavior in low and high literates. Frontiers in Psychology, 2, 285. https://doi.org/10.3389/fpsyg.2011.00285

Jescheniak, J. D., \& Levelt, W. J. M. (1994). Word frequency effects in speech production: Retrieval of syntactic information and of phonological form. Journal of Experimental Psychology: Learning Memory, and Cognition, 20, 824-843. https://doi. org/10.1037//0278-7393.20.4.824

Kirby, J. R., Parrila, R. K., \& Pfeiffer, S. L. (2003). Naming speed and phonological awareness as predictors of reading development. Journal of Educational Psychology, 95(3), 453-464. https://doi. org/10.1037/0022-0663.95.3.452

Kittredge, A. K., Dell, G. S., Verkuilen, J., \& Schwartz, M. F. (2008). Where is the effect of frequency in word production? Insights from aphasic picture naming errors. Cognitive Neuropsychology, 25(4), 463-492. https://doi.org/10.1080/02643290701674851

Kolinsky, R. (2015). How learning to read influences language and cognition. In A. Pollatsek \& R. Treiman (Eds.), The Oxford handbook of reading (pp. 377-393). New York, NY: Oxford University Press.

Kolinsky, R., Leite, I., Carvalho, C., Franco, A., \& Morais, J. (2018). Completely illiterate adults can learn to decode in 3 months. Reading and Writing, 31(3), 649-677. https://doi.org/10.1007/ s11145-017-9804-7

Kolinsky, R., Verhaeghe, A., Fernandes, T., Mengarda, E. J., GrimmCabral, L., \& Morais, J. (2011). Enantiomorphy through the looking glass: Literacy effects on mirror-image discrimination. Journal of Experimental Psychology: General, 140, 210-238. https://doi. org/10.1037/a0022168

Kosmidis, M. H., Kyrana, T., \& Folia, V. (2006). Lexical processing in illiteracy: Effect of literacy or education? Cortex, 42, 1021-1027. https:// doi.org/10.1016/S0010-9452(08)70208-9

Kosmidis, M. H., Zafiri, M., \& Politimou, N. (2011). Literacy versus formal schooling: Influence on working memory. Archives of Clinical Neuropsycholy, 26(7), 575-582. https://doi.org/10.1093/arclin/ acr063

Landerl, K., Ramus, F., Moll, K., Lyytinen, H., Leppänen, P. H. T., Lohvansuu, K., ... Valdois, S. (2013). Predictors of developmental dyslexia in European orthographies with varying complexity. Journal of Child Psychology and Psychiatry, 54(6), 686-694. https://doi. org/10.1111/jcpp.12029

Lau, J. K., Humphreys, G. W., Douis, H., Balani, A., Bickerton, W.-L., \& Rotshtein, P. (2015). The relation of object naming and other visual speech production tasks: A large scale voxel-based morphometric study. Neuroimage: Clinical, 7, 463-475. https://doi.org/10.1016/j. nicl.2015.01.015

Lervåg, A., \& Hulme, C. (2009). Rapid automatized naming (RAN) taps a mechanism that places constraints on the development of early reading fluency. Psychological Science, 20(8), 1040-1048. https://doi. org/10.1111/j.1467-9280.2009.02405.x

Levelt, W. J. M. (2001). Spoken word production: A theory of lexical access. PNAS, 98(23), 13464-13471. https://doi.org/10.1073/ pnas. 231459498

Luce, P. A., David, B. P., \& Stephen, D. G. (1990). Similarity neighborhoods of spoken words. In G. T. M. Altmann (Ed.), Cognitive models of speech processing (pp. 122-147). Cambridge, MA: MIT Press.

Metsala, J. L. (1997). Spoken word recognition in reading disabled children. Journal of Educational Psychology, 89, 159-169. https://doi. org/10.1037/0022-0663.89.1.159

Meyer, A.S., Sleiderink, A. M., \& Levelt, W. J. M. (1998). Viewing and naming objects: Eye movements during noun phrase production. Cognition, 66, B25-B33. https://doi.org/10.1016/S0010-0277(98)00009-2

Misra, M., Katzir, T., Wolf, M., \& Poldrack, R. A. (2004). Neural systems for rapid automatized naming in skilled readers: Unraveling the RAN-reading relationship. Scientific Studies of Reading, 8(3), 241256. https://doi.org/10.1207/s1532799xssr0803_4

Moll, K., Ramus, F., Bartling, J., Bruder, J., Kunze, S., Neuhoff, N., ... Landerl, K. (2014). Cognitive mechanisms underlying reading and spelling development in five European orthographies. Learning and Instruction, 29, 65-77. https://doi.org/10.1016/j.learninstruc.2013.09.003

Morais, J., \& Kolinsky, R. (2001). The literate mind and the universal human mind. In E. Dupoux (Ed.), Language, brain, and cognitive development. Cambridge, MA: The MIT Press.

Mousikou, P., \& Rastle, K. (2015). Lexical frequency effects on articulation: A comparison of picture naming and reading aloud. Frontiers in Psychology, 6, 1571. https://doi.org/10.3389/fpsyg.2015.01571

Muneaux, M., \& Ziegler, J. (2004). Locus of orthographic effects in spoken word recognition: Novel insights from the neighbour generation task. Language and Cognitive Processes, 19(5), 641-660. https://doi. org/10.1080/01690960444000052 
Newman, R. S., \& German, D. J. (2005). Life span effects of lexical factors on oral naming. Language and Speech, 48, 123-156. https://doi.org/1 $0.1177 / 00238309050480020101$

Norton, E. S., \& Wolf, M. (2012). Rapid automatized naming (RAN) and reading fluency: Implications for understanding and treatment of reading disabilities. Annual Review of Psychology, 63, 427-452. https://doi.org/10.1146/annurev-psych-120710-100431

Pacheco, A., Reis, A., Araújo, S., Inácio, F., Petersson, K. M., \& Faísca, L. (2014). Dyslexia heterogeneity: Cognitive profiling of Portuguese children with dyslexia. Reading and Writing: An Interdisciplinary Journal, 27, 1529-1545. https://doi.org/10.1007/ s11145-014-9504-5

Peterson, R. L., Arnett, A. B., Pennington, B. F., Byrne, B., Samuelsson, S., $\&$ Olson, R. K. (2017). Literacy acquisition influences children's rapid automatized naming. Developmental Science, 21(3), e12589. https:// doi.org/10.1111/desc.12589

Powell, D., Stainthorp, R., Stuart, M., Garwood, H., \& Quinlan, P. (2007). An experimental comparison between rival theories of rapid automatized naming performance and its relationship to reading. Journal of Experimental Child Psychology, 98, 46-68. https://doi.org/10.1016/j. jecp.2007.04.003

Price, C. J., McCrory, E., Noppeney, U., Mechelli, A., Moore, C. J., Biggio, N., \& Devlin, J. T. (2006). How reading differs from object naming at the neuronal level. Neurolmage, 29, 643-648. https://doi. org/10.1016/j.neuroimage.2005.07.044

Rastle, K., McCormick, S. F., Bayliss, L., \& Davis, C. J. (2011). Orthography influences the perception and production of speech. Journal of Experimental Psychology-Learning Memory and Cognition, 37(6), 15881594. https://doi.org/10.1037/a0024833

Reis, A., \& Castro-Caldas, A. (1997). Illiteracy: A cause for biased cognitive development. Journal of the International Neuropsychological Society, 3(5), 444-450.

Reis, A., Guerreiro, M., \& Peterson, K. M. (2003). A sociodemographic and neuropsychological characterization of an illiterate population. Applied Neuropsychology, 10(4), 191-204. https://doi.org/10.1207/ s15324826an1004_1

Sadat, J., Martin, C. D., Costa, A., \& Alario, F. (2014). Reconciling phonological neighborhood effects in speech production through single trial analysis. Cognitive Psychology, 68, 33-58. https://doi. org/10.1016/j.cogpsych.2013.10.001

Saletta, M., Goffman, L., \& Brentari, D. (2016). Reading skill and exposure to orthography influence speech production. Applied Psycholinguistics, 37(2), 411-434. https://doi.org/10.1017/s0142716415000053

Schatschneider, C., Carlson, C. D., Francis, D. J., Foorman, B. R., \& Fletcher, J. M. (2002). Relationship of rapid automatized naming and phonological awareness in early reading development: Implications for the double-deficit hypothesis. Journal of Learning Disabilities, 35, 245-256. https://doi.org/10.1177/002221940203500306

Smith, A. C., Monaghan, P., \& Huettig, F. (2014). Literacy effects on language and vision: Emergent effects from an amodal shared resource (ASR) computational model. Cognitive Psychology, 75, 28-54. https:// doi.org/10.1016/j.cogpsych.2014.07.002

Soares, A. P., Machado, J., Costa, A., Iriarte, A., Simões, A., Almeida, J. J., ... Perea, M. (2015). On the advantages of word frequency and contextual diversity measures extracted from subtitles: The case of Portuguese. Quarterly Journal of Experimental Psychology, 68(4), 680696. https://doi.org/10.1080/17470218.2014.964271

Soares, A. P., Costa, A. S., Machado, J., Comesaña, M., \& Oliveira, H. (2017). The Minho Word Pool: Norms for imageability, concreteness and subjective frequency for 3,800 Portuguese words. Behavior Research Methods. https://doi.org/10.3758/s13428-016-0767-4

Szekely, A., \& Bates, E. (2000). Objective visual complexity as a variable in studies of picture naming. Center for Research in Language (Vol. 12). La Jolla, San Diego: University of California.
Torgesen, J. K., Wagner, R. K., \& Rashotte, C. A. (1994). Longitudinal studies of phonological processing and reading. Journal of Learning Disabilities, 27, 276-286. https://doi.org/10.1177/00222194940270050

Vaessen, A., Bertrand, D., Tóth, D., Csépe, V., Faísca, L., Reis, A., \& Blomert, L. (2010). Cognitive development of fluent word reading does not qualitatively differ between transparent and opaque orthographies. Journal of Educational Psychology, 102, 827-842. https:// doi.org/10.1037/a0019465

Ventura, P., Kolinsky, R., Fernandes, S., Querido, J.-L., \& Morais, J. (2007). Lexical restructuring in the absence of literacy. Cognition, 105, 334361. https://doi.org/10.1016/j.cognition.2006.10.002

Ventura, P., Kolinsky, R., Querido, J.-L., Fernandes, S., \& Morais, J. (2007). Is phonological encoding in naming influenced by literacy? Journal of Psycholinguistic Research, 36, 341-360. https://doi.org/10.1007/ s10936-006-9048-1

Verhagen, W., Aarnoutse, C., \& van Leeuwe, J. (2008). Phonological awareness and naming speed in the prediction of dutch children's word recognition. Scientific Studies of Reading, 12(4), 301-324. https://doi.org/10.1080/10888430802132030

Vitevitch, M. S. (1997). The neighborhood characteristics of malapropisms. Language \& Speech, 40, 211-228. https://doi. org $/ 10.1177 / 002383099704000301$

Vitevitch, M. S., \& Luce, P. A. (2016). Phonological neighborhood effects in spoken word perception and production. Annual Review of Linguistics, 2, 7.1-7.20. https://doi.org/10.1146/ annurev-linguistics-030514-124832

Walley, A. C., Metsala, J. L., \& Garlock, V. M. (2003). Spoken vocabulary growth: Its role in the development of phoneme awareness and early reading ability. Reading and Writing: an Interdisciplinary Journal, 16, 5-20.

Wei, W., Georgiou, G. K., \& Deng, C. (2015). Examining the cross-lagged relationships between RAN and word reading in Chinese. Scientific Studies of Reading, 19, 446-455. https://doi.org/10.1080/10888438 .2015.1077447

Wolf, M., \& Bowers, P. G. (1999). The double-deficit hypothesis for the developmental dyslexias. Journal of Educational Psychology, 91, 415438. https://doi.org/10.1037/0022-0663.91.3.415

Wolf, M., Bowers, P. G., \& Biddle, K. (2000). Naming-speed processes, timing, and reading: A conceptual review. Journal of Learning Disabilities, 33(4), 387-407. https://doi.org/10.1177/002221940003300409

Wolff, U. (2014). RAN as a predictor of reading skills, and vice versa: Results from a randomised reading intervention. Annals of Dyslexia, 64, 151-165. https://doi.org/10.1007/s11881-014-0091-6

Ziegler, J. C., Bertrand, D., Tóth, D., Csépe, V., Reis, A., Faísca, L., ... Blomert, L. (2010). Orthographic depth and its impact on universal predictors of reading: A cross-language investigation. Psychological Science, 21, 551-559. https://doi.org/10.1177/0956797610363406

Ziegler, J. C., \& Goswami, U. (2005). Reading acquisition, developmental dyslexia, and skilled reading across languages: A psycholinguistic grain size theory. Psychological Bulletin, 131(1), 3-29. https://doi. org/10.1037/0033-2909.131.1.3

How to cite this article: Araújo S, Fernandes T, Huettig F. Learning to read facilitates the retrieval of phonological representations in rapid automatized naming: Evidence from unschooled illiterate, ex-illiterate, and schooled literate adults. Dev Sci. 2019;22:e12783. https://doi.org/10.1111/desc.12783 


\section{APPENDIX A}

TAB LE A1 Picture names of the objects used in the rapid naming task, for each experimental condition (English translation in parenthesis)

\begin{tabular}{|c|c|c|c|}
\hline \multicolumn{2}{|c|}{ High-frequency names } & \multicolumn{2}{|c|}{ Low-frequency names } \\
\hline Balança (bed) & Estrela (star) & Apito (whistle) & Punhal (dagger) \\
\hline Cruz (cross) & Flor (flower) & Concha (shell) & Raquete (racket) \\
\hline Livro (book) & Avião (plane) & Bóia (float) & Melão (melon) \\
\hline Chave (key) & Janela (window) & Machado (axe) & Frasco (jar) \\
\hline
\end{tabular}

Note. PN, Phonological neighborhood.

TAB LE A2 Object names' characteristics: mean word frequency (per million), length in number of letters and phonemes, number of phonological (PN) and orthographic neighbors (ON), and the mean word frequency of neighbors per million word, and visual complexity. Standard error of the mean is presented in parenthesis

\begin{tabular}{|c|c|c|c|c|}
\hline \multirow[b]{2}{*}{ Variables } & \multicolumn{2}{|c|}{ High-frequency } & \multicolumn{2}{|c|}{ Low-frequency } \\
\hline & Large PN & Small PN & Large PN & Small PN \\
\hline Number of letters & $5.20(0.49)$ & $5.20(58)$ & $5.40(0.51)$ & $5.80(0.37)$ \\
\hline Number of phonemes & $4.60(0.40)$ & $5.20(0.58)$ & $4.60(0.40)$ & $5.40(0.24)$ \\
\hline Frequency of PN & $6.51(3.46)$ & $8.84(4.01)$ & $13.94(8.55)$ & $3.32(1.77)$ \\
\hline Frequency of $\mathrm{ON}$ & $10.62(6.06)$ & $7.76(3.90)$ & $4.19(3.46)$ & 3.17 (1.89) \\
\hline Visual complexity & $10.15(1.42)$ & $10.43(1.19)$ & $11.98(1.31)$ & 8.89 (1.03) \\
\hline
\end{tabular}

